\title{
Bermuda's Tale of Two Time Series: Hydrostation S and BATS*
}

\author{
Helen E. Phillips ${ }^{+}$ \\ CSIRO Marine Research, Hobart, Tasmania, Australia \\ TERrence M. Joyce \\ Woods Hole Oceanographic Institution, Woods Hole, Massachusetts
}

(Manuscript received 16 March 2005, in final form 21 March 2006)

\begin{abstract}
This paper describes the oceanic variability at Bermuda between 1989 and 1999, recorded in two overlapping hydrographic time series. Station S and Bermuda Atlantic Time Series Study (BATS), which are 60 $\mathrm{km}$ apart, both show that a multidecadal trend of deep warming has reversed, likely as a result of the increased production of Labrador Sea Water since the early 1980s. In addition to recording similar changes in watermass properties, the two time series show similar mean vertical structure and variance as a function of pressure for temperature, salinity, and density above $1500 \mathrm{dbar}$. The seasonal cycles of these water properties at the two sites are statistically indistinguishable. The time series differ in the individual eddy events they record and in their variability below $1500 \mathrm{dbar}$. The two time series are used to investigate the propagation of eddy features. Coherence and phase calculated from the low-mode variability of density show westward propagation at $\sim 3 \mathrm{~cm} \mathrm{~s}^{-1}$ of wavelengths around $300-500 \mathrm{~km}$. Satellite altimeter data are used to provide a broader spatial view of the eddy (or wave) field near Bermuda.
\end{abstract}

\section{Introduction}

Because of its isolation from large landmasses and its steep topography, the island of Bermuda has become the staging point for blue water cruises into the Sargasso Sea with only a few hours of ship transit from St. George's Harbor. Bermuda has been the host for two ocean time series from 1989 until the present. In 1989, the Bermuda Atlantic Time Series Study (BATS) was begun as an interdisciplinary study of fundamental physical, chemical, and biological ocean processes throughout the water column with nearly monthly cruises to a site approximately $75 \mathrm{~km}$ southeast (SE) of

* Woods Hole Oceanographic Institution Contribution Number 11344

+ Current affiliation: Centre for Marine Science, University of Tasmania, Hobart, Tasmania, Australia.

Corresponding author address: Dr. Helen Phillips, Centre for Marine Science, University of Tasmania, Private Bag 77, Hobart, TAS 7001, Australia.

E-mail: h.e.phillips@utas.edu.au

DOI: $10.1175 / J P O 2997.1$

(C) 2007 American Meteorological Society
Bermuda $\left(31^{\circ} 40^{\prime} \mathrm{N}, 64^{\circ} 10^{\prime} \mathrm{W}\right)$ in water approximately $4500 \mathrm{~m}$ deep. BATS became one of two key islandbased sites for investigators of the U.S. Joint Global Ocean Flux Study (JGOFS) Program (U.S. JGOFS Steering Committee 1990), the other site being the Hawaiian Ocean Time Series (HOTS) in Hawaii. It is unclear to us why the site chosen for BATS differed from one defined previously: Station S, where serial hydrographic observations were begun in 1954. Station $\mathrm{S}$ is in shallower water (ca. 3300-m depth) and is located 25 $\mathrm{km} \mathrm{SE}$ of Bermuda $\left(32^{\circ} 10^{\prime} \mathrm{N}, 64^{\circ} 30^{\prime} \mathrm{W}\right)$ on a line from the island out to BATS (Fig. 1). Cruises to Station S have been approximately biweekly and have continued now for $50 \mathrm{yr}$ with few interruptions. Some anecdotal information for the selection of the BATS site over Station $\mathrm{S}$ is that project scientists wanted to be in deeper water and outside any possible "island effects." We will henceforth use $\mathrm{S}$ for Station $\mathrm{S}$ for brevity and to distinguish from the symbol for salinity.

Previous interest in the Bermuda time series has been as a window into interannual to decadal climate variability (e.g., Talley and Raymer 1982; Jenkins 1982; Roemmich 1990; Talley 1996; Joyce and Robbins 1996). Station $\mathrm{S}$ has provided one of the few long-term time 


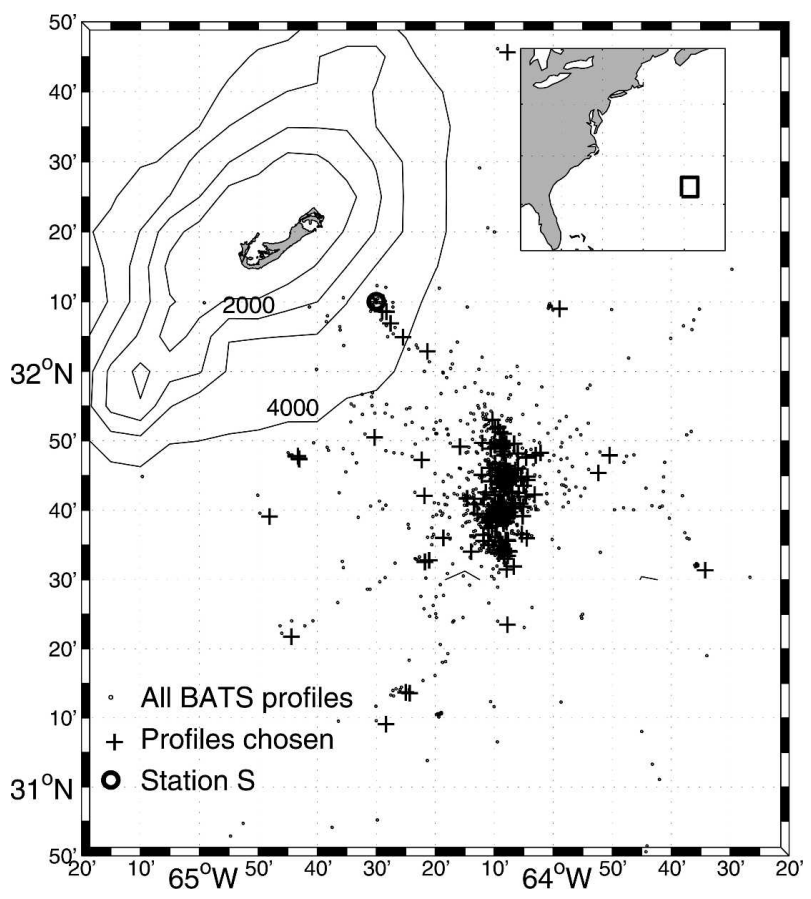

FIG. 1. Location of Station S (black circle) and BATS sites near Bermuda. Black dots show the full range of BATS sampling; gray plus signs are the deep stations chosen for this study. The inset shows how the study site fits within a basin-scale view.

series of temperature, salinity, and pressure from the surface to the (relatively) deep ocean. In these studies variability at S, particularly in North Atlantic Subtropical Mode Water (known as $18^{\circ}$ Water; Worthington 1959) characteristics, has been used as a proxy for variability over a much larger region of the western North Atlantic Ocean subtropical gyre. There is some evidence to support this assumption. Molinari et al. (1997) have shown that interannual variability in $100-\mathrm{m}$ temperature from expendable bathythermographs (XBTs) to the west of Bermuda $\left(32^{\circ}-33^{\circ} \mathrm{N}, 70^{\circ} \mathrm{W}\right)$, which they use as a proxy for thermocline displacement, is highly coherent with sea level variability at Bermuda. World Ocean Circulation Experiment (WOCE) section A22 along $66^{\circ} \mathrm{W}$ shows relatively weak meridional gradients in temperature, salinity, and density down to about $1500 \mathrm{~m}$ across $27^{\circ}-37^{\circ} \mathrm{N}$ (Joyce et al. 2001). Recent, broad-scale mapping of $18^{\circ}$ Water properties from the World Ocean Database 2001 (Conkright et al. 2002) and profiling floats shows that the volume-averaged temperature of $18^{\circ}$ Water across the western North Atlantic is highly correlated with the temperature of the potential vorticity $(\mathrm{PV}$ ) minimum layer at $\mathrm{S}$ (Kwon and Riser 2004).

While our interest in climate variability continues and recent observations will be shown to have significant departures from long-term trends reported earlier (up until 1990), our goal in this study is also to better understand the nature of the variability and, in particular, what different information is found in the two time series at Bermuda. Would BATS serve as a site for extending $\mathrm{S}$ into the future and preserve the same signals as presently found at $\mathrm{S}$ or are two distinct sites necessary for the foreseeable future? We will take mainly a statistical viewpoint using $11 \mathrm{yr}$ of physical data (temperature $T$, salinity $S$, and pressure $P$ during 1989-99 inclusive) now available to us.

In the following section we introduce the datasets and the method used to construct monthly time series over $11 \mathrm{yr}$. We also describe the mean seasonal cycle. In section 3 we examine anomalies from the mean seasonal cycle and explore the changes in water mass properties of different layers. A significant result of our study is exposing a reversal in the long-term trend of increasing temperature and salinity in the 1500-2500dbar layer. We then use spectral properties of density anomalies to characterize the propagation of features from BATS to S. In section 4 we present some results using $9 \mathrm{yr}$ of satellite altimeter measurements made in the waters surrounding Bermuda in order to better understand the nature and possible sources of the superannual variability recorded in both time series at Bermuda.

\section{Estimation of the mean seasonal cycle}

The data at S and BATS were collected with various types of CTD systems, and water sample salinities were used to calibrate the CTD salinities. Each BATS cruise made multiple casts (Fig. 1) at various locations near the target site. In a given month, we selected the deepest cast in excess of $4100 \mathrm{dbar}$ closest to a central BATS site $\left(31^{\circ} 40^{\prime} \mathrm{N}, 64^{\circ} 10^{\prime} \mathrm{W}\right)$, ignoring shallower or further removed casts. The irregularly spaced monthly BATS data were linearly interpolated to the 15 th of each month, to give a total of 132 months covering the period January 1989-December 1999. Gaps in the time series were linearly interpolated in time.

Although the S data were collected at nearly 2 times the BATS sampling rate, we linearly interpolated to the 15th of each month as we did for BATS, making the temporal sampling of the two time series essentially identical. The temporal subsampling of $S$ is only to facilitate comparison between the two records and does not indicate that we regard the extra sample per month as unimportant.

The 2-dbar CTD data at both stations were subsampled to 10-dbar intervals. BATS data were truncated to a maximum pressure of $2600 \mathrm{dbar}$, the deepest regular sampling depth at the shallower $\mathrm{S}$. 

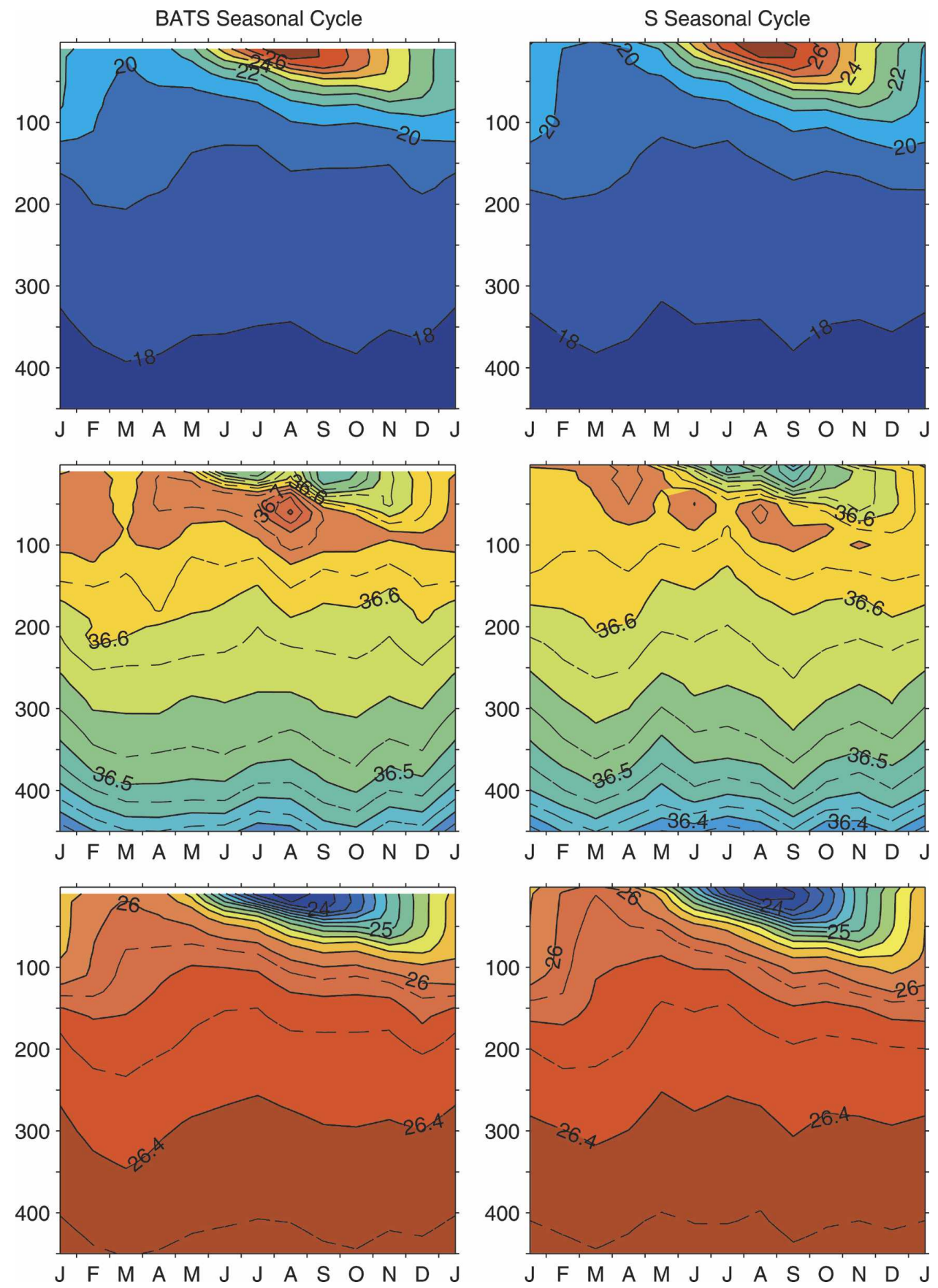

FIG. 2. Seasonal cycles of (top) temperature $\left({ }^{\circ} \mathrm{C}\right)$, (middle) salinity (psu), and (bottom) potential density $\left(\mathrm{kg} \mathrm{m}^{-3}\right)$ at (left) BATS and (right) S.

Using the 11 years of monthly measurements at both sites, we have estimated a mean annual cycle by averaging together data from the same months in each of the 11 years, which we will henceforth call the seasonal cycle (Fig. 2). We estimated the statistical significance of the seasonal signal at each pressure using the record mean variance in anomalies from the seasonal cycle in each month and the number of degrees of freedom based on the number of years when that month had an observation. Temperature $T$, salinity $S$, and potential density $\sigma$ are the basic physical variables of interest and none of these shows any significant seasonal signal below 400 dbar. For salinity at BATS, for example (Fig. 2, middle left), no significant seasonal salinity signal can be detected below $120 \mathrm{dbar}$ and no temperature signal can be detected below 360 dbar. Density variations, 
however, persist to 400 dbar, presumably because higher-frequency variability in $T$ and $S$ cancels so that $\sigma$ has a higher signal-to-noise ratio. Frankignoul (1981), using an earlier 24-yr time segment of S, found little significant seasonal cycle in temperature at pressures exceeding $300 \mathrm{dbar}$, similar to what we see for our later period.

There are visible differences between the two seasonal cycles in Fig. 2. For example, $\mathrm{S}$ experiences both deeper penetration of seasonal warming and stronger erosion of the seasonal thermocline/pycnocline; and the subsurface salinity maximum in summer is stronger at BATS than at S. To determine whether the mean seasonal cycles at BATS and S are the same in a statistical sense, we used a two-tailed test (Emery and Thomson 2001) to see if the mean difference of each variable, for each month of the year and depth, was significantly different from the error of the mean difference. At no time were any of the mean differences significant at the $95 \%$ level for any variable (temperature, salinity, or density). We would have preferred to have a longer base time series for this comparison as only 11 years (degrees of freedom) were available, but it would seem that the mean seasonal signals at both sites are indistinguishable.

The seasonal cycle for our 11-yr period is essentially the same as described by Talley (1996) for the period 1954-78. In Fig. 2 we see that the deepest local winter mixed layers $(<200-\mathrm{m}$ depth) occur at the time of the maximum surface density in March. As noted by Talley and Raymer (1982), surface waters at Bermuda in the winter are lighter and warmer than the underlying $18^{\circ}$ Water. Thus, the ventilation of $18^{\circ}$ Water does not occur locally at Bermuda in the mean. The arrival of the $\mathrm{PV}$ minimum associated with $18^{\circ}$ Water can be seen as an increase in thickness between the 26.4 and 26.5 isopycnals (Fig. 2, bottom panels). For our period of study, the $\mathrm{PV}$ minimum associated with $18^{\circ}$ Water arrives at both Bermuda stations in July, approximately 4 months after the maximum local surface density at Bermuda. Similar delays in the arrival of the $18^{\circ}$ Water at Bermuda were suggested by Talley and Raymer (1982) using PV (6-month delay) and Jenkins (1982) using dissolved oxygen (1-3-month delay). One would expect that any difference between the arrival times of an active tracer like PV and a water property like oxygen must be due to propagation effects, which do not affect oxygen. However, the above delays indicate that the oxygen signal travels faster than the PV signal. It is not clear to us why this is so, but it may be that the two delays are not directly comparable because they are calculated from different datasets. Furthermore, the oxygen data, which came from bottles, had much poorer vertical resolution than PV and may not have been able to separate $18^{\circ}$ Water from locally formed mode water.

In addition to Talley and Raymer's (1982) description of the seasonal cycle, Fig. 2 shows that in spring the seasonal thermocline forms before any significant appearance of lower salinities, which are associated with summer rainfall. The seasonal halocline is therefore shallower than the seasonal thermocline at Bermuda. High salinity values found near the sea surface in late winter appear to deepen with the deepening of the summer pycnocline as though being subducted under the less dense, fresher water of the seasonal pycnocline/ halocline.

The $18^{\circ}$ Water was warmer and less dense than normally found at Bermuda (Talley 1996) for our 11-yr period of study. This is the signature of the positive phase of the North Atlantic Oscillation (NAO) that dominated during this time. A stronger pressure difference between the atmospheric subpolar low and the subtropical high pressure cells shifts storm tracks to a northerly path so that the $18^{\circ}$ Water formation region experiences less convective overturning in winter and less (or no) $18^{\circ}$ Water is produced (Joyce et al. 2000). In section 3, we discuss in more detail the link between $18^{\circ}$ Water potential vorticity at Bermuda and the NAO.

\section{Monthly anomalies at Bermuda}

Monthly anomalies were constructed by removing the mean seasonal cycle. The long-term mean vertical structure at the two sites is shown in Fig. 3. The variability of the monthly anomalies (Fig. 4, solid lines) is greatest within the permament pycnocline/thermocline for $T-S$, while the potential density variability is largest within the seasonal pycnocline. The low variability region from 200 to 400 dbar between the two pycnoclines is occupied by the $18^{\circ}$ Water. The structure of the mean and standard deviation at the two sites is very similar between the two sites for all three variables, with slightly higher variability in the deep water at BATS, and in the seasonal and permanent halocline salinity at BATS. We next define one of the dominant components in the time series-that due to vertical heave of the pycnocline.

The potential density anomalies at each depth were normalized by their standard deviation at that depth. An empirical orthogonal function (EOF) analysis was performed on the normalized anomalies at each site. The lowest two vertical modes contained 52\% (54\%) and $14 \%(20 \%)$ of the record variance for modes 1 and 2 for S (BATS). The lowest mode contains variability that is in phase throughout the water column while mode 2 has one zero crossing at a pressure of approxi- 

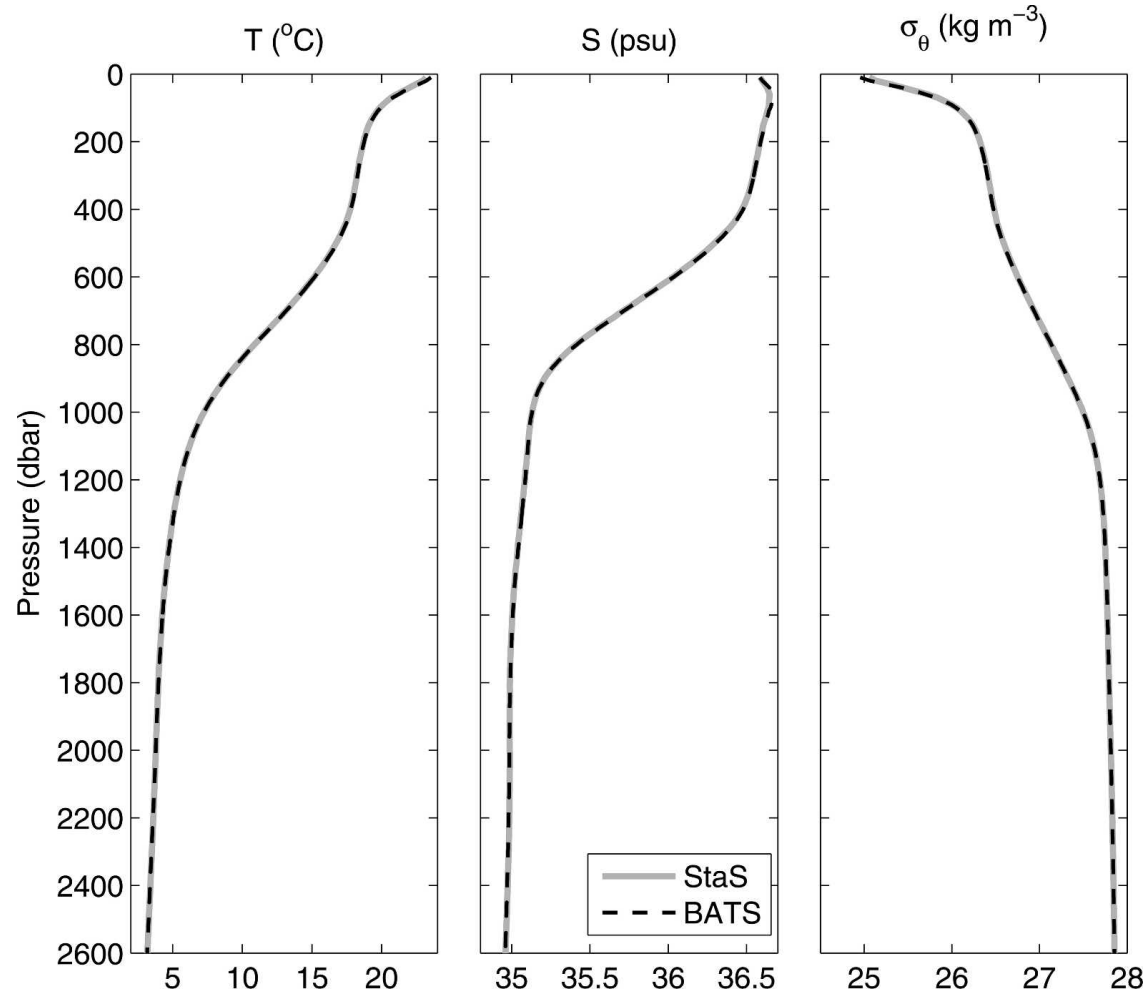

FIG. 3. Ensemble mean vertical structure at the two Bermuda sites.

mately 1500 dbar. The time series of the respective principal components (PCs) were then normalized to have unit variance, and $T$ and $S$ were regressed against each PC throughout the water column. The resulting regressions contain the $T-S$ structure that is correlated with density fluctuations for the lowest vertical modes. Given that these modes are dominated by vertical heaving of the water column, the $T-S$ regressions contain the $T-S$ variability associated with this vertical heave. What remains after this regression we define as the $T-S$ residuals, and these contain variability associated with higher vertical modes and with water mass changes, or $T-S$ variability on constant potential density surfaces. The standard deviation of the residuals (Fig. 4, dashed lines) is greatly reduced within the permanent pycnocline where coherent heaving can produce large $T-S$ fluctuations. Once the variability associated predominantly with vertical heave is removed the residual time series can be examined for evidence of watermass variability.

\section{a. Watermass changes at Station $S$ and BATS}

We have selected portions of the water column, corresponding to four of the levels in Joyce and Robbins (1996) to illustrate temporal changes (Fig. 5). The time series of residual temperature and salinity have been smoothed in time with one pass of a 1/4:1/2:1/4 filter to reduce some of the high-frequency variability. The surface layer (0-200 dbar) contains variability subject to air-sea exchange locally, and we find that $T$ variability is not well correlated with $S$ variability. Allowing for the different integral time scales for each level, the $T-S$ covariability in the 0-200-dbar layer is barely significant at the $95 \%$ level. In contrast, $T-S$ are significantly correlated at more than the $99 \%$ level in the $18^{\circ}$ Water layer (200-400 dbar), the pycnocline (500-1000 dbar), and the deep layer (1500-2500 dbar). In calculating statistical significance the number of degrees of freedom is estimated as the duration of the time series divided by the integral time scale at each depth.

We now turn to the covariability between the two sites. The pycnocline (500-1000 dbar) is the only layer in which residual variability in temperature observed at Station S is not significantly correlated with that observed at BATS. The same is true for salinity at the two sites. Recall here that most of the variability in the pycnocline was removed by the heave decomposition.

Joyce and Robbins (1996) investigated long-term trends in the 1500-2500-dbar layer at $\mathrm{S}$ and found a significant warming from 1954 up through 1990 (see regression line in their Fig. 7, lower panel). We have found the opposite trend. Within this layer, there is a 

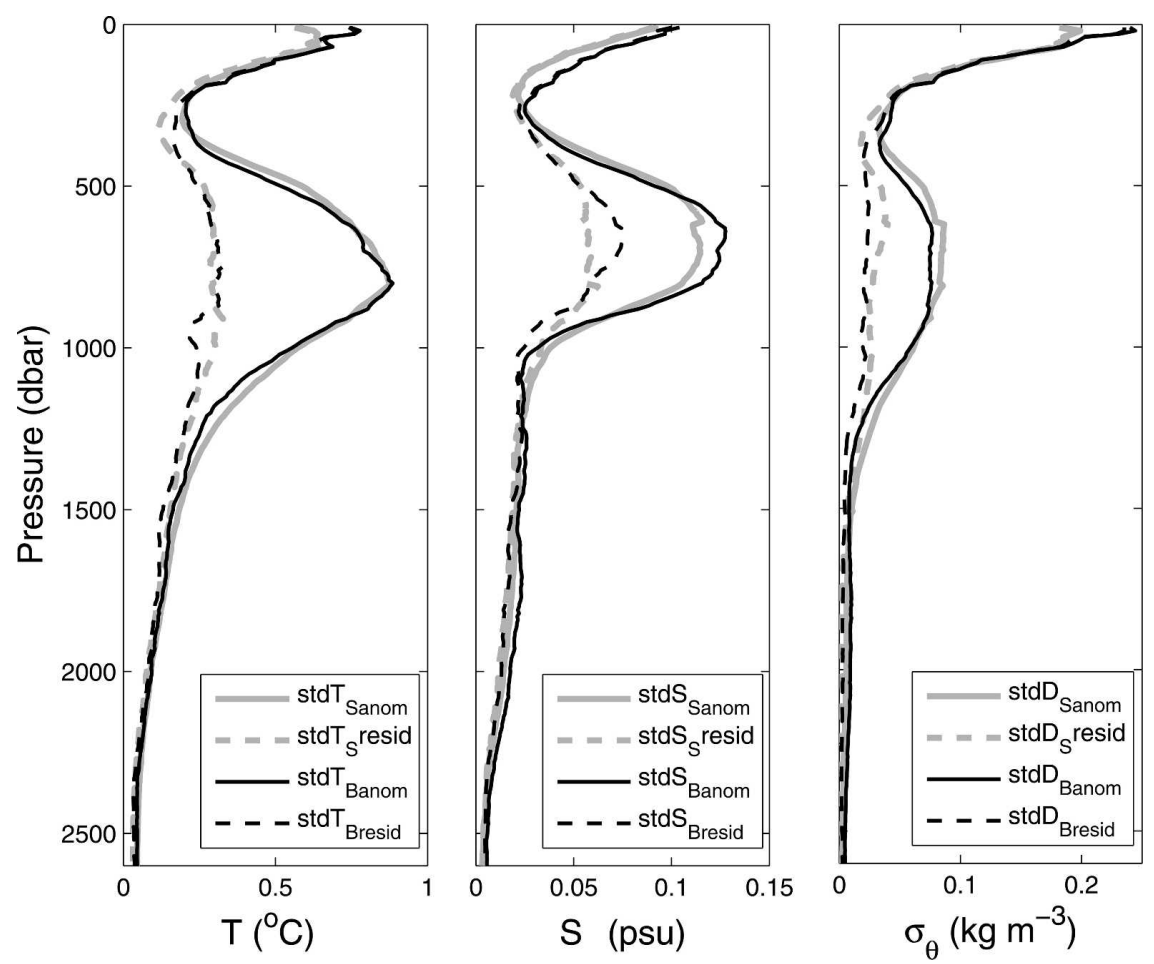

FIG. 4. Standard deviation vs pressure for the monthly anomalies of temperature, salinity, and potential density for Station S (heavy lines) and BATS (thin lines). The residual standard deviation is also shown for each of the two sites (dashed lines), obtained by removing the signal correlated with the lowest two potential density EOF modes by linear regression.

strong cooling and freshening trend during the 1990s at both S and BATS. A least squares linear fit to the data yields a slope of $-0.13 \pm 0.01^{\circ} \mathrm{C}\left(-0.08 \pm 0.01^{\circ} \mathrm{C}\right)$ and $-0.017 \pm 0.002 \mathrm{psu}(-0.010 \pm 0.001 \mathrm{psu})$ at $\mathrm{S}$ (BATS). The error bars denote the $99 \%$ confidence limits based on the Student's $t$ test. Curry et al. (1998) showed that temperature variability at these depths at Bermuda could be linked with thickness changes of Labrador Sea Water (LSW) 6 years earlier. In the early 1980s the LSW thickness in the Labrador Sea began to increase and its temperature began to decrease (Dickson et al. 1996). This trend continued until the early 1990s. Lagging the timing of this LSW renewal by $6 \mathrm{yr}$ aligns with the cooling and freshening we see at Bermuda. Around 1996, LSW was at its thickest and coldest since 1930. Since then, the NAO has moved out of a sustained positive phase, and the LSW thickness has begun to decline (Curry et al. 1998). Thus, the decade-long cooling and freshening in the deep water at Bermuda (Fig. 5 , lower panels) will likely end in 2002, $6 \mathrm{yr}$ after the end of strong renewal of LSW. In Fig. 6, where we have added back in the time mean fields, the renewal of cold low-salinity water at Bermuda between 1990 and 1999 can be clearly seen. Plus signs mark the $T-S$ properties averaged over the period 1954-87 (Joyce and Robbins
1996). The top panel in Fig. 6 shows the full column $T-S$ relationship while the lower panel zooms in on the LSW layer. Temperature and salinity data from BATS are now available up until the end of 2003. The coldest and freshest LSW arrived at BATS in July 2000, somewhat earlier than expected. Thereafter, $T$ and $S$ have increased in the layer by about $0.05^{\circ} \mathrm{C}$ and $0.003 \mathrm{psu} \mathrm{yr}^{-1}$.

Dickson et al. (2002) have pointed out that substantial changes can be seen in the denser water below the level of the LSW, but we see little significant change in $T-S$ between 3000 and 4000 dbar at BATS. As this pressure range does not permit any comparison between the two sites, we will not look into deep changes at Bermuda.

Within the thermocline (500-1000 dbar), the Bermuda records indicate that after high temperatures in the 1997-98 period, the temperature (and salinity) have steadily decreased. The extended BATS time series shows this cooling continues until mid-2001 and is followed by a sudden warming in mid-late 2001 of $\sim 0.5^{\circ} \mathrm{C}$ and a cooling during $2002-03$ of $\sim 0.3^{\circ} \mathrm{C}$. Freshening (salinity increase) is associated with cooling (warming). Based on transatlantic hydrographic sections, Bryden et al. (2005) report an increase in 400-800-m temperatures of $1^{\circ}-2^{\circ} \mathrm{C}$, and a deepening of the $14^{\circ}, 12^{\circ}$, and $9.5^{\circ}$ 
A
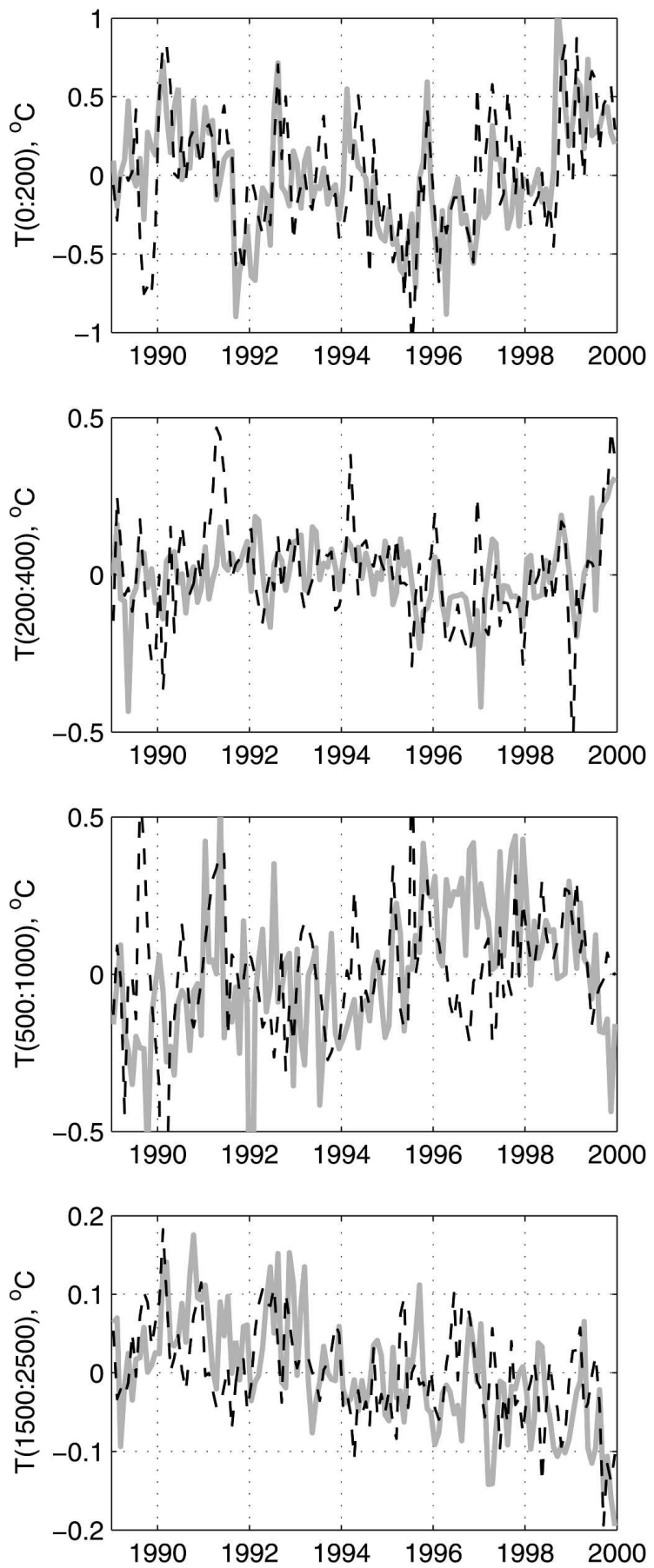

B
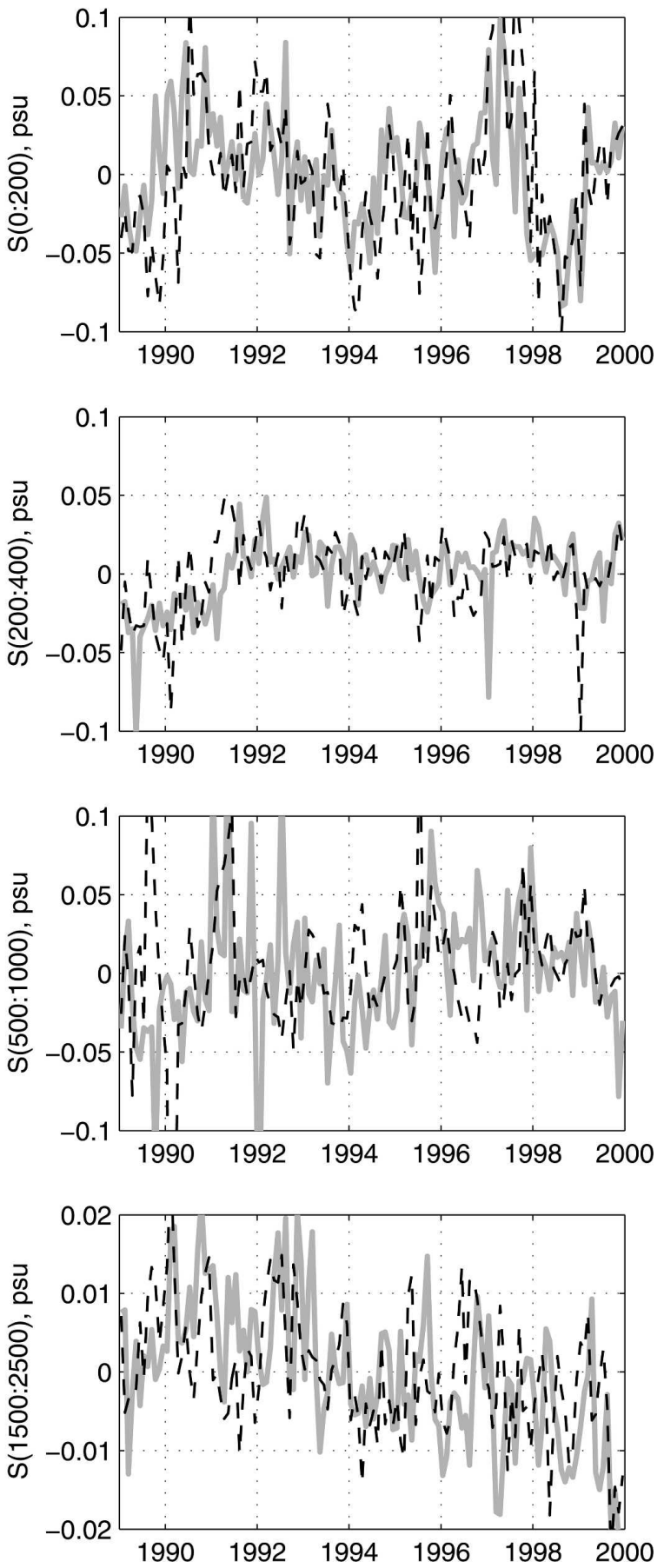

FIG. 5. Time series of residuals of (a) temperature and (b) salinity for Station S (solid lines) and BATS (dashed) for four different pressure levels, as indicated on the axes.

isotherms by $75 \mathrm{~m}$ at the western end of $28^{\circ} \mathrm{N}$ in 2004 compared with transects in 1957, 1981 and 1992. Associated with this steepening of the thermocline is a larger midocean southward flow above $1000 \mathrm{~m}$. The apparent lack of agreement between our two studies could be due either to the distance from $28^{\circ} \mathrm{N}$ to Bermuda, or to the fact that the results of Bryden et al. include the heave signal, but it has been removed from ours. The $T-S$ changes in the residuals are often obscured by a large heave signal. When heave is restored to the Ber- 

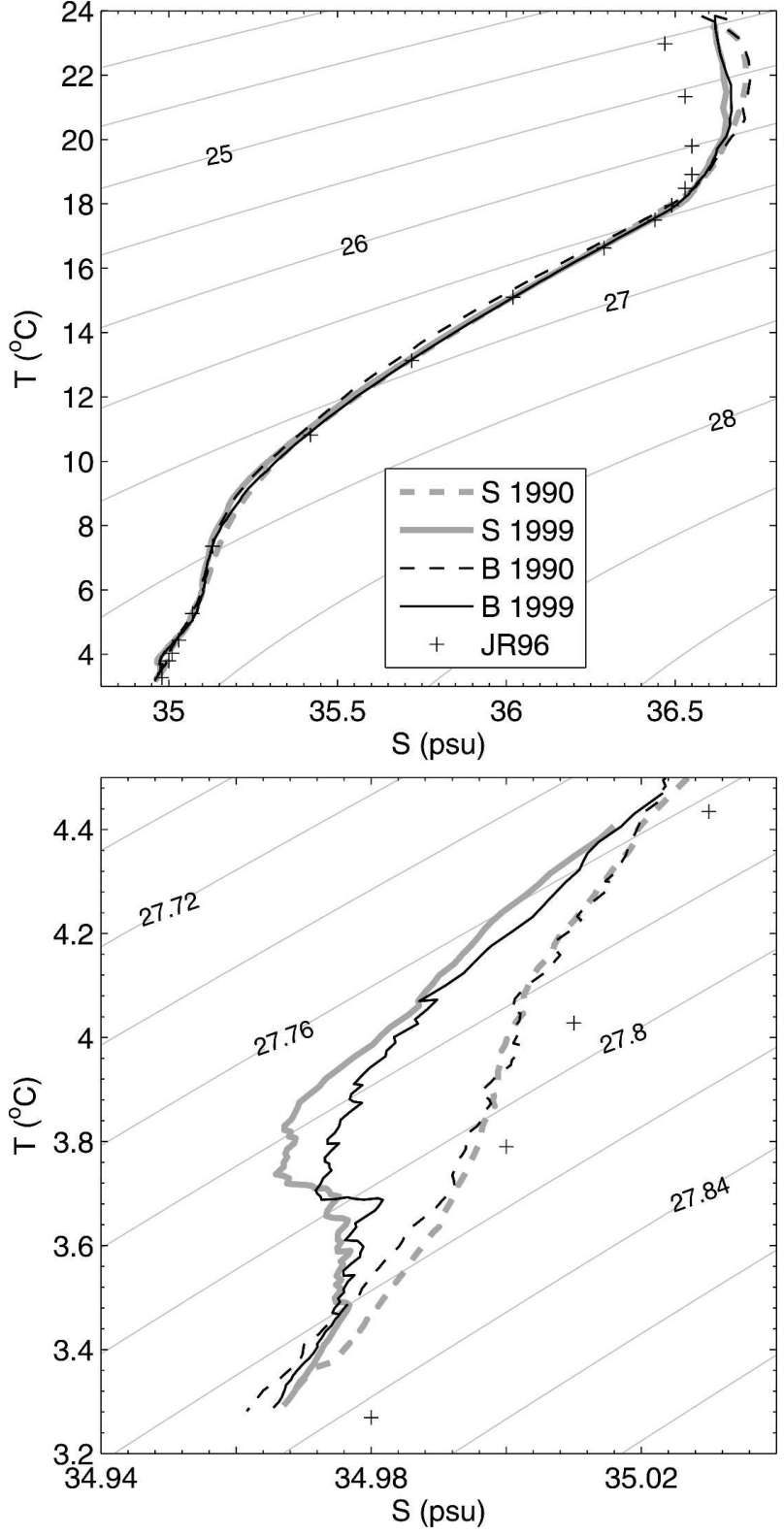

FIG. 6. Annual mean $T-S$ properties for two different time periods (1990 and 1999) are contrasted. (top) Full water column. (bottom) Portion of the water column associated with LSW at Bermuda. The 1954-87 mean T-S (Joyce and Robbins 1996) is marked with plus signs.

muda time series we see an increase in annual average temperatures of $\sim 1^{\circ} \mathrm{C}$ from 1992 to 2002, with warmest temperatures in 1995, and 1998 being relatively cool. Thus, if 2004 at Bermuda proves to be just as warm as 2002, then the Bermuda records would show the same thermocline warming (with heave included) found at the western end of the $28^{\circ} \mathrm{N}$ section.

The variability of the $18^{\circ}$ Water potential vorticity $[\mathrm{PV}=-(f / \rho)(\partial \rho / \partial z)]$ at Bermuda was shown by Joyce et al. (2000) to be closely tied to wintertime atmospheric variability associated with the NAO. During high NAO periods (with large sea level pressure difference between the Azores and Iceland), the winter storm track was displaced northward and the Sargasso Sea experienced mild winters. During low NAO periods, a southerly storm track brought colder winters to the western subtropical gyre and Bermuda and thus low $\mathrm{PV}$ in the $18^{\circ}$ Water. The time series of this PV minimum layer (Fig. 7) shows a large decrease in PV in 1995/96 and an increase in the potential density of the $\mathrm{PV}$ minimum. This renewal of $18^{\circ} \mathrm{Water}$ is clear in both time series and can be linked to changes in the NAO. Since 1996 the NAO has become more positive (Fig. 8), the PV minimum has increased (Fig. 7), and the $18^{\circ}$ Water layer shows warmest temperatures at the beginning of the year 2000 (Fig. 5b). The 2000-03 BATS data show that $18^{\circ}$ Water temperature and PV continue to be high.

The seasonal station-based NAO index in Fig. 8 is calculated from monthly changes in a normalized 3-month moving average (Hurrell et al. 2003; http:// www.cgd.ucar.edu/cas/jhurrell/indices.html). It is plotted together with the 200-400-dbar layer-averaged PV for the $18^{\circ}$ Water at both Bermuda sites. The PV and NAO series track each other with the PV lagging behind the NAO by 6 months. By examining the correlation between the interannual variability of the NAO in a particular month and the PV variability (S and BATS average) throughout the year we have found that it is the NAO interannual variability in winter/ spring months that is responsible for the correlation with PV we see about 6 months later. The delay of approximately 4 months we found in section 2 between late winter surface density and the arrival of the minimum PV of $18^{\circ}$ Water at Bermuda is consistent with this lagged correlation between the NAO and PV. By averaging the correlation coefficients (after detrending) over the same lags/leads for all possible months, one sees a lag of the PV following the NAO by 4-7 months (Fig. 9). There is a slight suggestion of a PV signal leading NAO by 2 months (Fig. 9), but the time series are too short for any confidence in the latter.

\section{b. Spectral properties of the low-mode density variability}

Returning now to the EOF decomposition of density, recall that the two lowest EOFs/PCs were used to estimate the vertical heave and this was then used to regress and remove covarying $T-S$ variability. From the density, regression against the gravest modes can be used together with the mean density gradient to estimate the vertical amplitude of the heave as a function 

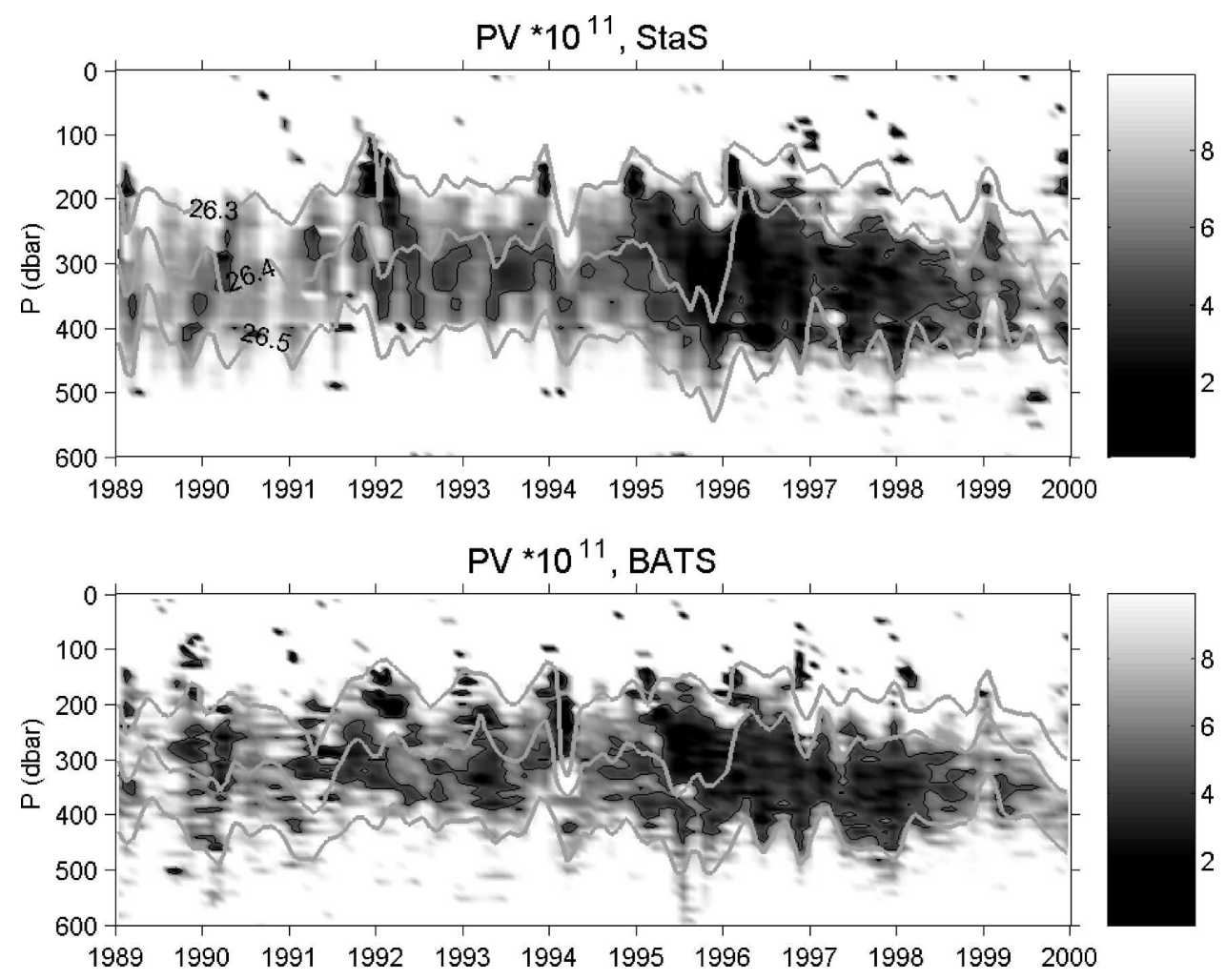

FIG. 7. Potential vorticity $[\mathrm{PV}=-(f / \rho)(\partial \rho / \partial z)]$ at (top) Station S and (bottom) BATS sites for the portion of the water column associated with $18^{\circ}$ Water. Three selected potential density surfaces (contours) are plotted showing the change in density of the PV minimum layer over the 11-yr record.

of pressure for each of the two modes. The heave can then be used to study the temporal variability of the dynamical features that cause the heave (e.g., eddies or waves). The vertical amplitude of heave (Fig. 10) reveals a zero crossing in the second mode between 1300 and 1500 dbar, with somewhat smaller amplitude than the first mode. While the overall structure is similar for $\mathrm{S}$ and BATS, the latter clearly has more variability in the deeper water. Since BATS is in deeper water than $\mathrm{S}$, this difference is most likely due to either the shallower bottom at $\mathrm{S}$ restricting vertical motion at pressures in excess of 2000 dbar or the large spatial variability of the BATS sampling. This will be discussed later.

The time series of the principal components were spectrally analyzed using 50\% overlapping Hanning windows of 3-yr duration, giving an estimated 7 degrees of freedom (Fig. 11). We have plotted the variancepreserving form of the spectrum, with spectral density multiplied by frequency and plotted on a linear-semilog scale. There are differences in the location of some of the spectral peaks, possibly an indication that some of the high-frequency variability is not common to both time series. However, the message that there is strong energy at subannual periods is clear. For a frequency spectrum proportional to $\omega^{-1}$, the spectra in Fig. 11 would be flat. This "power law" appears to be the case for Bermuda, but with a concentration of spectral

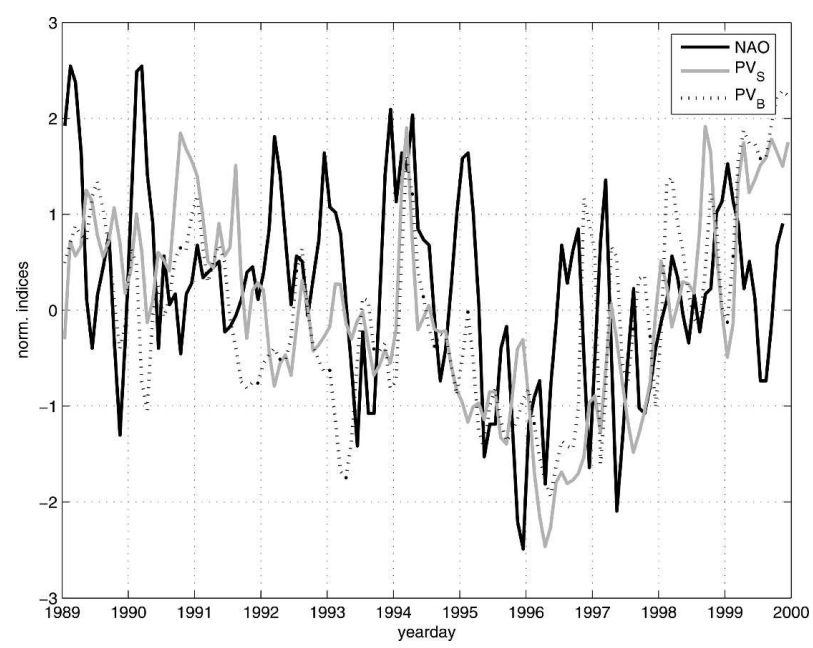

FIG. 8. Time series of 200-400-dbar-averaged PV at Station S (gray line) and BATS (dotted line), and the monthly variation of a station-based NAO index (black line). 


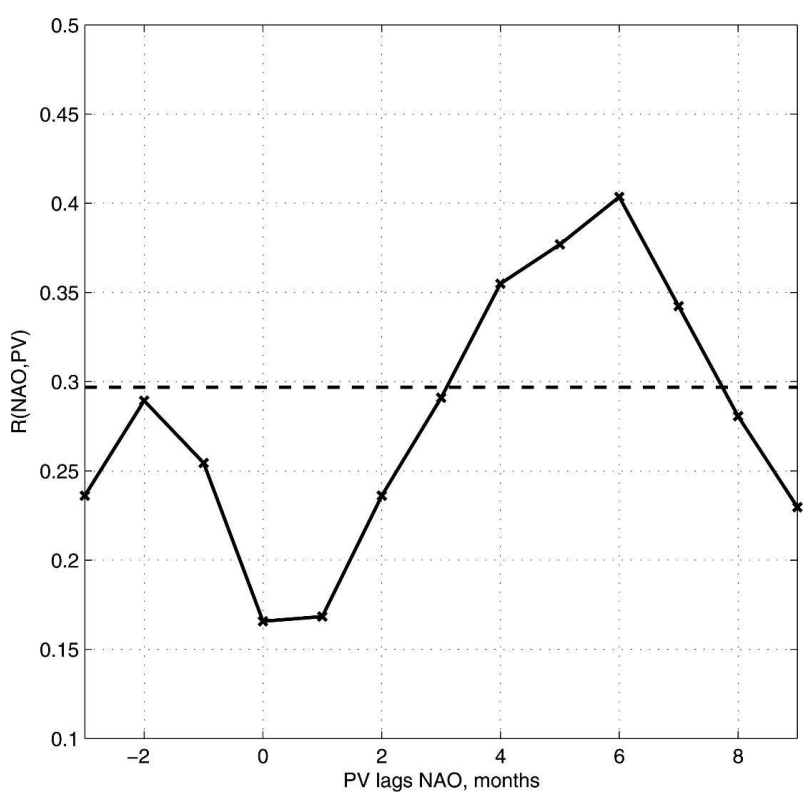

FIG. 9. Monthly time series of PV and the NAO index were detrended and a 2D lagged correlation was calculated by taking an interannual time series of PV from one month and correlating with an interannual time series of NAO index from another month. The correlation function was then averaged at each lag/ lead in order to construct an "ensemble average." The 95\% significance levels are shown taking into account the autocovariance structure of both time series. The level is correct only for zero lag and rises slightly away from this point. Significant correlations are mainly due to wintertime NAO variability (not shown).

power at subannual periods. For example, compare spectral levels for S, mode 1 , at periods of 2 years and longer with the higher levels at periods of 3-6 months. Wunsch (1972) suggested that internal tides could be aliased in the S time series (with exactly 14-day sampling) into energy at a period of approximately 8.6 months and that this might be affecting spectral estimation in his 13 years of data. In our case, with monthly sampling, the $M_{2}$ tidal alias would have a period in excess of 30 yr. Frankignoul (1981), using a longer S time series of 24 years, found no evidence of a tidal alias peak at 8.6 months, and with better statistics than we can muster with only 11 years, showed that there was a concentration of spectral power at periods of a few months to a year, as is suggested in the present results. If not some tidal alias, what is the source of this variability in pycnocline displacement at Bermuda? Is it due to low-mode Rossby wave propagation or due to eddies? We combine the two Bermuda time series to address these questions.

The coherence and phase of the two PC time series from both sites were calculated in a manner similar to that followed for the spectral estimates (Fig. 12). When coherence is significant, one can usually identify spec- tral peaks in one or both of the time series. For mode 1, phase differences are positive with BATS leading S. At a period of 4 months this phase difference, $\pi / 4$, is significant. With a distance of separation between the sites of $60 \mathrm{~km}$ ( $35 \mathrm{~km}$ zonally), one would estimate a wavelength of $480 \mathrm{~km}(280 \mathrm{~km})$ for this energy, suggesting a zonal phase speed of $2.7 \mathrm{~cm} \mathrm{~s}^{-1}$ westward. The second mode has much less power but also shows evidence of this "westward" propagation tendency with coherent power at a period between 8 and 10 months leading at BATS by a phase of $\pi / 2$, giving a wavelength of half of that estimated above, and a phase speed of $0.05-0.07$ $\mathrm{cm} \mathrm{s}^{-1}$. Overall lower coherence and the possibility of phase "wraparound" makes it difficult to extract much more from the second mode.

Thinking about sources of variability, one might imagine surface forcing by winds as a large contributor. Indeed, Sturges et al. (1998) explained much of the interannual sea level variability at Bermuda in terms of wind-generated, first-vertical-mode, internal Rossby waves coming from generation regions to the east of Bermuda and propagating westward. With much of the low-mode energy at Bermuda found at superannual frequencies, what might the energy source be? Eddies passing by Bermuda have long been thought to play an important role in sea level and thermocline depth variability (Schroeder and Stommel 1969). Osychny and Cornillon (2004) used altimeter data to examine this problem from a different, wavelike perspective, to which we now turn.

\section{Sources of superannual energy at Bermuda: Altimeter measurements}

Osychny and Cornillon (2004) have presented wave characteristics of zonally propagating features in the North Atlantic with periods longer than 2 months using altimeter sea surface height (SSH) data. They find that near Bermuda westward-propagating waves of shorter than annual frequency dominate the frequency spectra and are associated with wavelengths of $500 \mathrm{~km}$ and greater. They do not address meridional propagation of the features but suggest that the region of the Grand Banks is a likely source for much of the variability on the western side of the basin, with wave fronts propagating to the southwest.

To further explore the wave characteristics of variability in the vicinity of Bermuda we also turn to altimeter data. We use optimally interpolated weekly gridded maps of SSH anomalies with a resolution of $13^{\circ}$ (Le Traon et al. 2001) provided by the Archiving, Validation, and Interpretation of Satellite Oceanographic data (AVISO) group. We examine the time series over the period January 1993 to December 2001 over the 

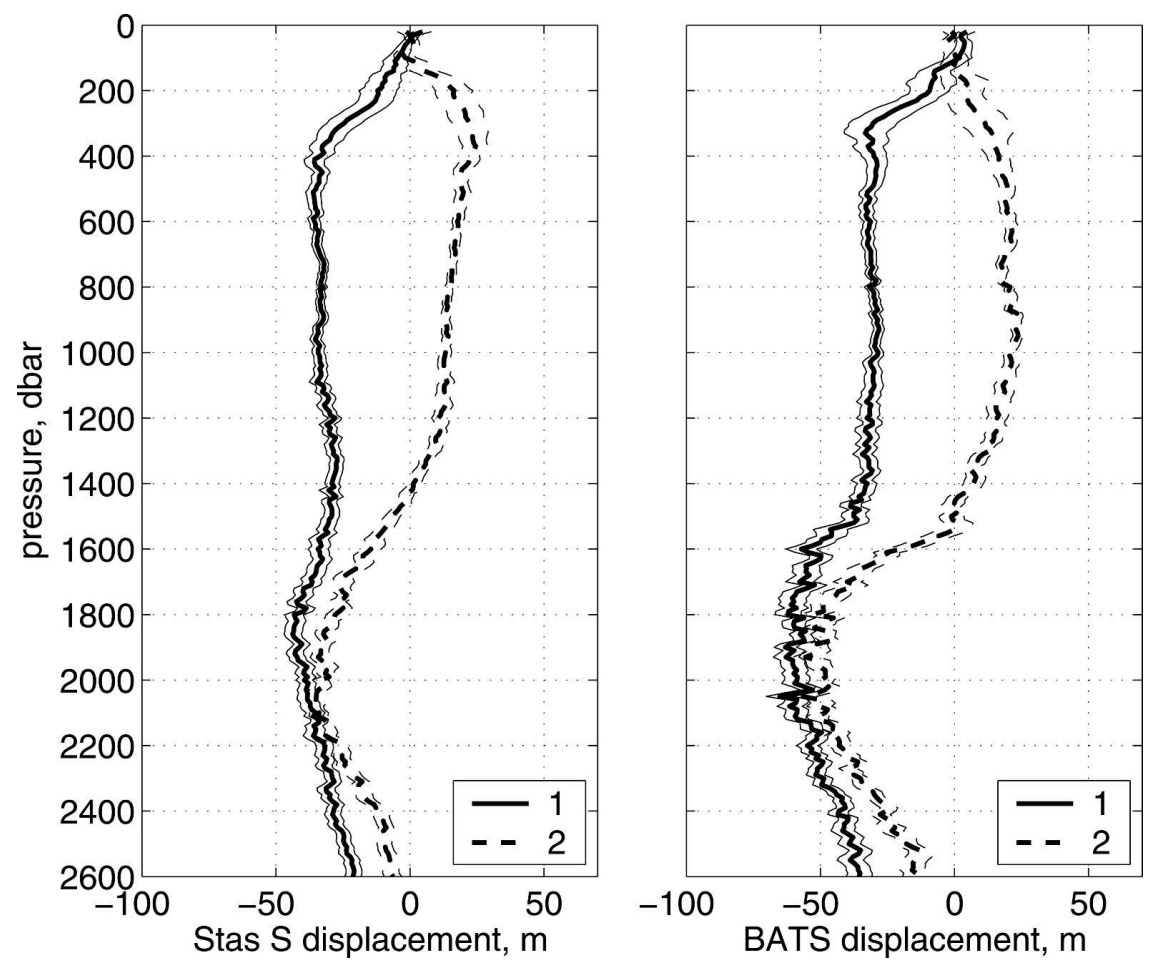

FIG. 10. Vertical displacement $(\mathrm{m})$ required to account for potential density variability associated with lowest two EOFs for $\sigma_{\theta}$. Thin lines show $95 \%$ significance limits for each EOF. (left) Station S and (right) BATS.

area $20^{\circ}-40^{\circ} \mathrm{N}, 75^{\circ}-45^{\circ} \mathrm{W}$. We remove a large-scale steric signal, which is the mean annual cycle of SSH anomalies averaged over the subtropical western north Atlantic $\left(20^{\circ}-34^{\circ} \mathrm{N}, 75^{\circ}-45^{\circ} \mathrm{W}\right)$, avoiding the region of the Gulf Stream. Hovmoeller diagrams of the anomalies after the steric signal is removed (not shown), called SSH residuals, show clear westward propagation, as previously found (e.g., Osychny and Cornillon 2004). Time-latitude Hovmoeller diagrams (not shown), less commonly discussed than time-longitude diagrams, suggest meridional propagation of varying sign near Bermuda. In the analysis of altimeter data we associate the position $32^{\circ} \mathrm{N}, 64.5^{\circ} \mathrm{W}$ with Bermuda.

Spectral analysis of the SSH residuals near Bermuda, in the manner described for the hydrographic data, reveals energetic fluctuations with periods between 4 and 8 months in addition to a peak in energy around the annual frequency (not shown). To look more closely at the propagation characteristics of this variability we separate the SSH residuals into frequency bands between 4 and 12 months and then calculate zonal and meridional lagged autocorrelation functions (ACFs). By separating the signal into frequency bands we hope to determine whether the approximately 4-8-month period band found to be energetic in the spectra of the density PCs also stands out in the altimeter data.
We use Chebyshev type-I filters (Smith 2003) to separate the SSH residuals into frequency bands corresponding to periods of $<4,4-6,6-8,8-10,10-12$, and $>12$ months. The filter specification allows a $1-\mathrm{dB}$ ripple in the pass band and rolls off by $30 \mathrm{~dB} 1$ month either side of the pass band. For each filter band we calculate the zonal ACF as the ACF of the time series at $32^{\circ} \mathrm{N}, 64.5^{\circ} \mathrm{W}$ with those at all other grid points along $32^{\circ} \mathrm{N}$. The time series away from Bermuda are lagged by -200 to 200 days. Figure 13 shows the lagged zonal ACF of SSH residuals at $32^{\circ} \mathrm{N}$. Isolines of correlation coefficient that tilt upward to the left indicate westward propagation. Superimposed on the ACF contours are straight lines to indicate westward propagation at 5 and $6 \mathrm{~cm} \mathrm{~s}^{-1}$. Note the clear westward propagation in all frequency bands higher than annual, with remarkably similar speeds between 5 and $6 \mathrm{~cm} \mathrm{~s}^{-1}$. The cleanest signal of westward propagation is in the highestfrequency band, $\omega>(4 \text { months })^{-1}$. As one moves to a lower frequency the smooth westward propagation lines are progressively more interrupted by other patterns. For fluctuations with periods greater than 12 months propagation is still westward but slower, at approximately $1.3 \mathrm{~cm} \mathrm{~s}^{-1}$.

Zonal wavelengths estimated from the lagged zonal ACFs range from about $500 \mathrm{~km}$ for periods less than 4 

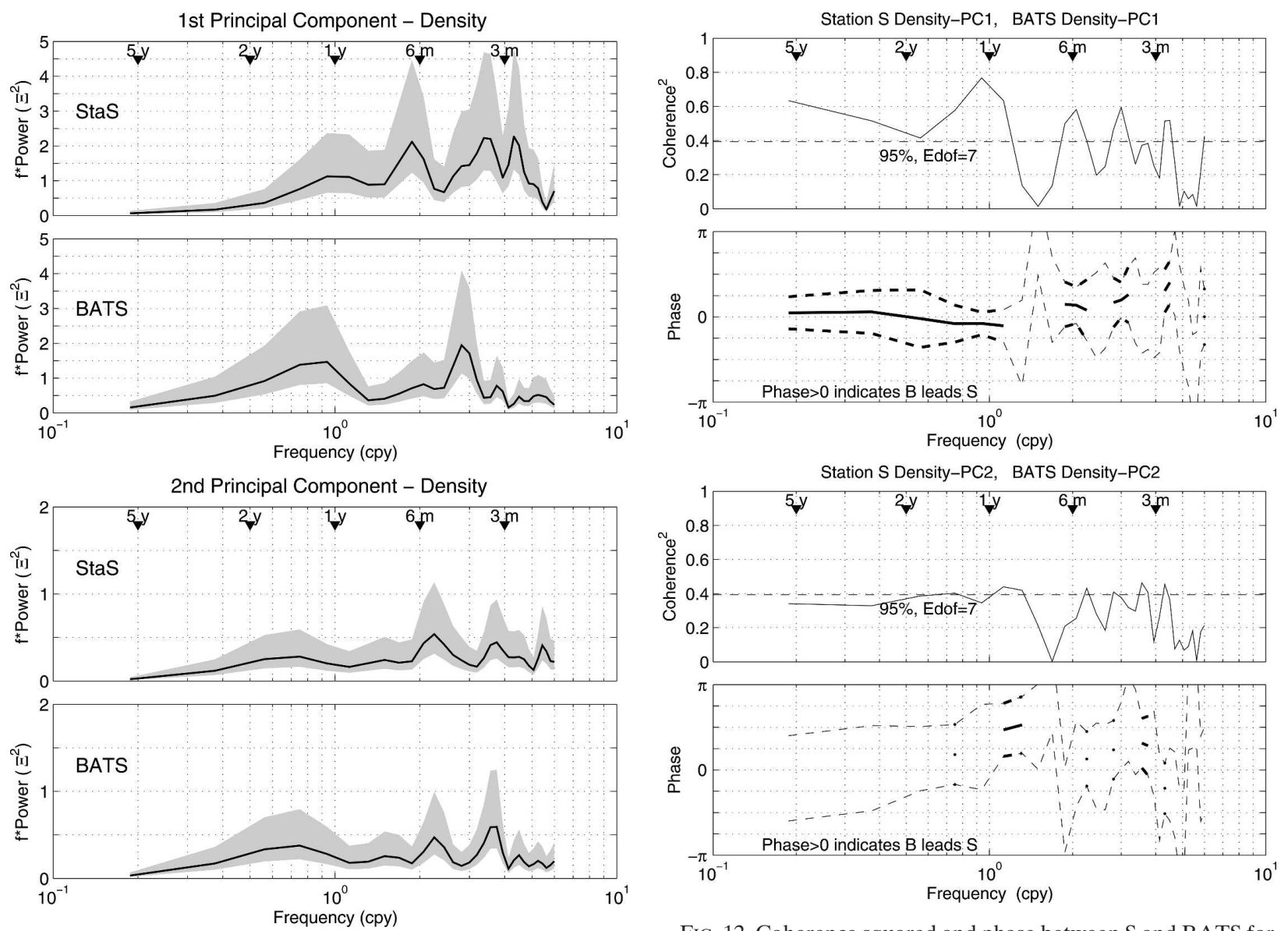

FIG. 12. Coherence squared and phase between S and BATS for

FIG. 11. Frequency spectra (variance-preserving form) of variability for the (top two) first and (bottom two) second potential density modes at the two sites.

months to about $800 \mathrm{~km}$ near the annual period. This is considerably larger than the Rossby radius of deformation $(\sim 30 \mathrm{~km})$ and explains the apparent nondispersive nature of the waves with periods less than annual.

The phase speeds calculated from the SSH residuals are considerably faster than linear theory predicts. When the background density field is unperturbed one can expect nondispersive Rossby waves to have phase speed $\omega / k=-\beta c^{2} / f^{2}$ (Gill 1982), where $f$ is the Coriolis parameter, and $\beta$ is the meridional gradient of $f$. We use a gravity wave phase speed of $c=3 \mathrm{~m} \mathrm{~s}^{-1}$ calculated using the buoyancy frequency profile from WOCE $66^{\circ} \mathrm{W}$ CTD temperature and salinity profiles averaged between $31^{\circ}$ and $33^{\circ} \mathrm{N}$. At $32^{\circ} \mathrm{N}$ this phase speed is -3 $\mathrm{cm} \mathrm{s}^{-1}$ [Chelton et al. (1998) estimate $-2.4 \mathrm{~cm} \mathrm{~s}^{-1}$ using gridded climatological data]. Killworth et al. (1997) have presented one mechanism by which the baroclinic east-west mean flows alter the background PV gradient to produce faster Rossby wave phase speeds than those predicted by linear theory. Advection by mean zonal the (top two) first and (bottom two) second potential density modes. Positive phase lag means BATS leads S.

flows will also affect the apparent frequency of Rossby waves: a westward zonal flow, for example, will increase the apparent frequency of a westward-propagating wave. Qiu et al. (1997) demonstrate the role of eddy dissipation off the equator in damping boundarygenerated free waves, leaving forced waves to dominate and thereby increasing the apparent phase speed to 2 times that predicted by linear theory. The gradual reduction in this dissipation as one approaches the equator gives rise to the gradual reduction of the apparent Rossby wave phase speed to the value predicted by linear theory. It is not clear from the ACF maps what variability is due to the westward translation of eddies and what is the signature of Rossby wave propagation. However, we note that the highest frequency for a baroclinic Rossby wave in an ocean with zero mean flow $\omega_{\max }=(-\beta c / 2 f)$ is $(6.3 \text { months })^{-1}$ at $32^{\circ} \mathrm{N}$. That we find energetic fluctuations with periods less than 6 months suggests that eddies play an important role.

The meridional ACFs in Fig. 14 show a much more complicated picture than their zonal counterparts. In 

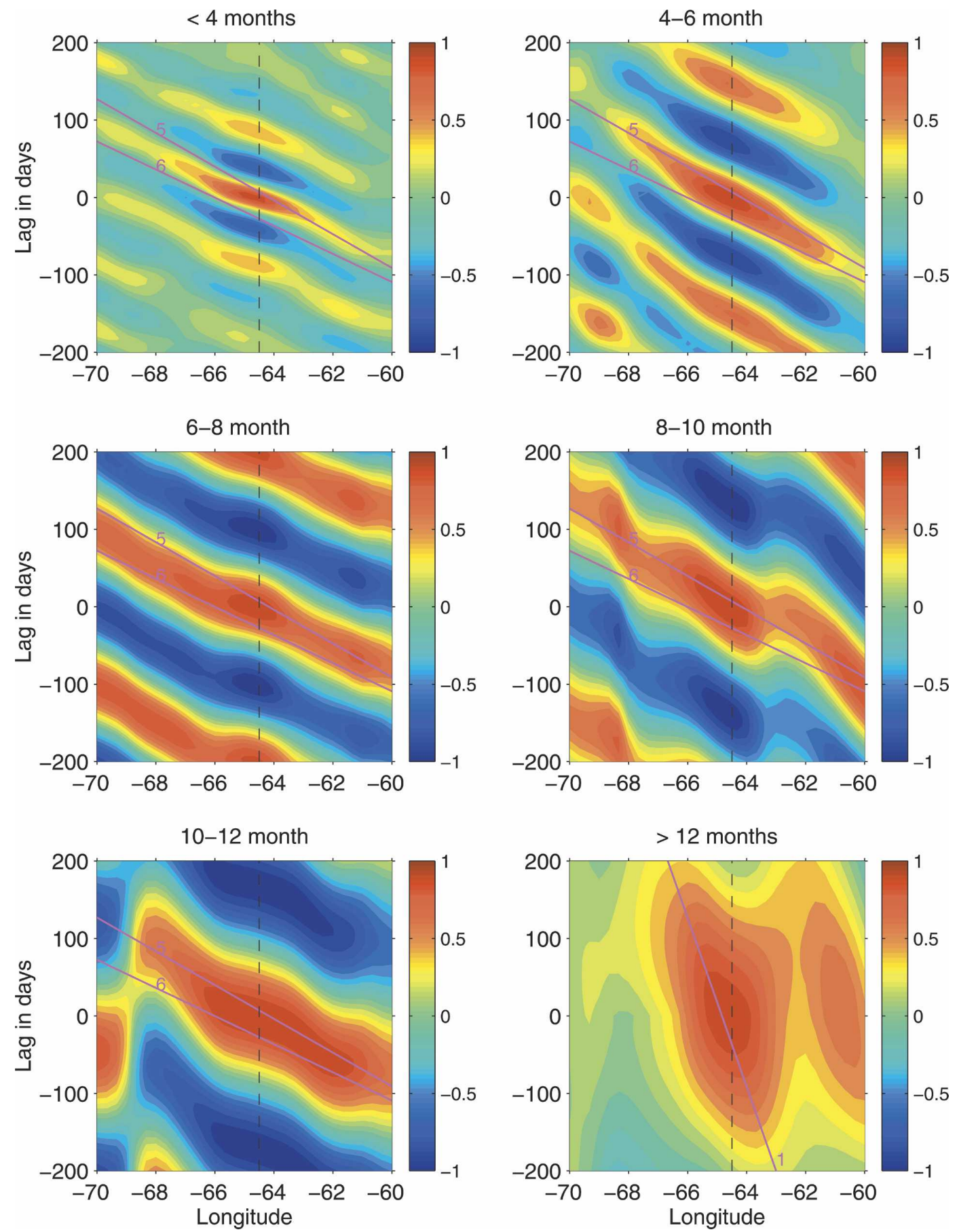

FIG. 13. Lagged zonal ACF of SSH anomalies at $32^{\circ} \mathrm{N}$ for six frequency bands. Straight lines labeled 5, 6, and 1 indicate westward propagation at 5,6 , and $1 \mathrm{~cm} \mathrm{~s}^{-1}$, respectively.

the highest frequency band ( $\tau<4$ months) there is no indication of meridional propagation. In the 4-6-month band we see northward propagation at $\sim 7 \mathrm{~cm} \mathrm{~s}^{-1}$ (tilting up to the right indicates northward propagation). In the next three bands we see propagation to both the north and the south, along with some fascinating inter- ference patterns. At 6-8 months, one might say that the bull's-eye centered on Bermuda indicates no meridional propagation. Nevertheless, surrounding patches of positive correlation line up intriguingly on both diagonals, possibly indicating a crossover of northward- and southward-propagating features. At $8-10$ months, a 

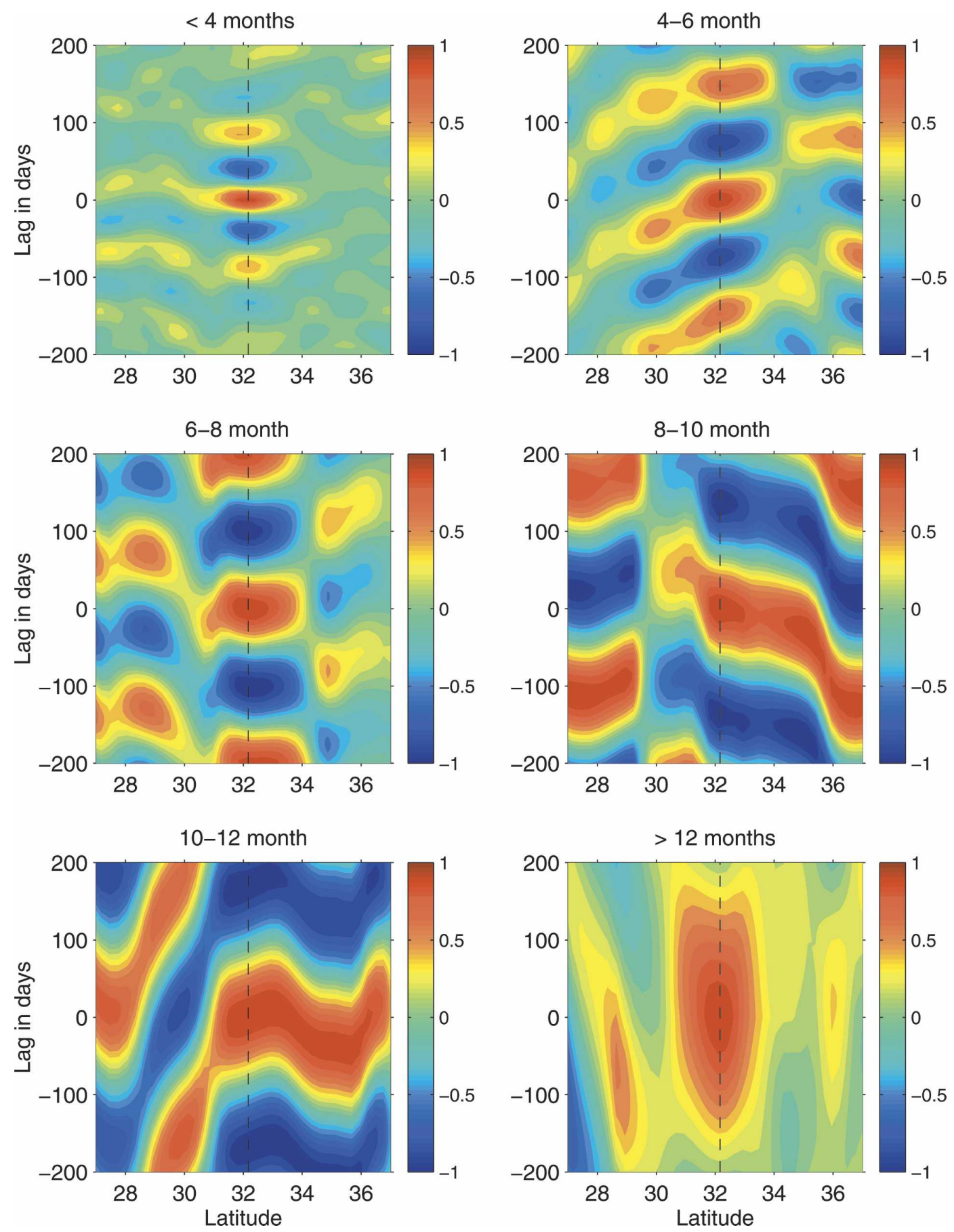

FIG. 14. Lagged meridional ACF of SSH anomalies at $64.5^{\circ} \mathrm{W}$ for six frequency bands. A slope that is upward to the right indicates northward propagation.

southward propagation at $-5.5 \mathrm{~cm}^{-1}$ dominates at Bermuda, but farther south a northward pattern takes over $\left(5.5 \mathrm{~cm} \mathrm{~s}^{-1}\right)$. A similar story is told in the 10-12-month band: southward propagation to the north of Bermuda $\left(-3.1 \mathrm{~cm} \mathrm{~s}^{-1}\right)$ and northward propagation to the south $\left(1.4 \mathrm{~cm} \mathrm{~s}^{-1}\right)$.
Since all frequencies show westward phase propagation (Fig. 13), northward phase propagation implies a source to the northeast of Bermuda (in the direction opposite that of the group velocity) if the variability we see is baroclinic Rossby waves. This is consistent with Osychny and Cornillon's (2004) hypothesis that the 
Grand Banks is a source of Rossby wave energy that propagates to the southwest all the way to the Bahamas. The southwestward phase propagation would imply a wave source to the southeast of Bermuda, whose identity we do not know.

Unlike the zonal propagation, which has relatively uniform phase speed from west to east of Bermuda (Fig. 13), meridional propagation is clearly banded and changes sign across the Sargasso Sea. It is not apparent from this study whether the locations of shifts in meridional direction are uniform in time, perhaps set by the large-scale flow, or whether what we are seeing is the random interaction of waves from different sources. The latitude of changes in the direction of propagation in the ACF plots is an average over the full time series. Reid's (1994) climatology shows complex flow paths across the Sargasso Sea, with northward and southward components that vary with depth.

In Fig. 15, we illustrate two things. First, the relative uniformity of westward phase propagation is not particular to $32^{\circ} \mathrm{N}$ but is also clear north and south of Bermuda (left panels). Westward phase speeds at 5-6 $\mathrm{cm} \mathrm{s}^{-1}$ are found from south of Bermuda to just south of the Gulf Stream. The changeover to eastward propagation associated with the Gulf Stream occurs around $37^{\circ} \mathrm{N}$.

In the right-hand panels in Fig. 15 we present the meridional ACF for the 6-8-month band at $56^{\circ}, 59^{\circ}$, $62^{\circ}$, and $65^{\circ} \mathrm{W}$. We find that the banding of meridional phase propagation seen in Fig. 14 is not unique to Bermuda, and therefore not the result of a scattering effect caused by the island. Eastward from Bermuda but still in the western side of the basin, the appearance of both northward- and southward-propagating features is common. Assuming that we can interpret the patterns of positive and negative correlations as wave crests and troughs, our ACF analysis implies the orientation of wave fronts drawn schematically in Fig. 16. The snapshot maps of wave fronts in Osychny and Cornillon (2004, their Fig. 11, particularly February 1996) show some resemblance to this schematic and extend our $32^{\circ} \mathrm{N}$ picture to the basin scale.

\section{Summary and discussion}

We have shown that BATS and S are statistically very similar. Their mean seasonal cycles of temperature, salinity, and density are indistinguishable, as are their mean vertical structures of those properties. The variance of temperature, salinity, and density as a function of pressure at BATS and $\mathrm{S}$ is also indistinguishable above 1500 dbar. In layers corresponding to $18^{\circ}$ Water and LSW, the time series from the two stations are well correlated once the variability due to vertical heave is removed. In the LSW layer (1500-2500 dbar), the 40-yr trend of warming and increasing salinity described by Joyce and Robbins (1996) has reversed in the 1990s. There is a distinct renewal of cold freshwater in this layer from 1990 to 1999 (Fig. 6), a result of the increased thickness of LSW since the early 1980s (Curry et al. 1998). In the $18^{\circ}$ Water layer (200-400 dbar) the arrival of a thick, dense layer of PV minimum water occurs in July 1996 in both time series, influenced by the late winter/early spring NAO 4-7 months earlier.

BATS and S differ in several important ways. First of all, S has higher temporal resolution, biweekly as compared with monthly at BATS, which we subsampled for the purpose of comparing with BATS. Station S also has a tightly constrained spatial location while sampling at BATS covers an area with a radius of up to $60 \mathrm{~km}$ from the mean position, presumably a consequence of the biological sampling strategy. Our estimate of vertical movement (Fig. 10), based on the low-mode density variability and vertical density gradient, suggests more vertical motion at BATS than at S below 1500 dbar. Since $\mathrm{S}$ is in shallower water than BATS (3300 m cf. $4500 \mathrm{~m}$ ), it is likely that the influence of the sea floor would restrict vertical motion at lower pressure at S. Or, could the spatial variation in station position at BATS play a role by contributing variability to the density field that is not explained by vertical motion?

In 1997 the WOCE $66^{\circ} \mathrm{W}$ hydrographic section sampled a slice of the Sargasso Sea, just to the west of Bermuda. Vertical sections of potential temperature $\theta$, salinity S, and neutral density $\gamma_{n}$ (Joyce et al. 2001, Plate 1) show relatively strong lateral gradients of these properties below 1500 dbar in the vicinity of Bermuda. Above 1500 dbar the isolines are flat in comparison. At $32^{\circ} \mathrm{N}$, the meridional gradients of $\theta, S$, and $\gamma_{n}$ are $\sim 0.08^{\circ} \mathrm{C}, \sim 0.03 \mathrm{psu}$, and $\sim 0.01 \mathrm{~kg} \mathrm{~m}^{-3}$, respectively, per $100 \mathrm{~km}$. Meridional fluctuations in the BATS position can be up to $60 \mathrm{~km}$ but are more frequently $25 \mathrm{~km}$. A meridional shift of $25 \mathrm{~km}$ could induce property fluctuations near $2000 \mathrm{~m}$ of $0.04^{\circ} \mathrm{C}, 0.015 \mathrm{psu}$, and $0.005 \mathrm{~kg}$ $\mathrm{m}^{-3}$, which are of the same order as the standard deviations of the property seasonal anomalies near 2000 dbar (Fig. 4).

In exploring the wavelike nature of variability recorded at S and BATS, we found that the low-mode variability at the two sites supported a westward propagation at $\sim 2.7 \mathrm{~cm} \mathrm{~s}^{-1}$. Gridded altimeter $\mathrm{SSH}$ data, however, suggested westward propagation at 5-6 $\mathrm{cm} \mathrm{s}^{-1}$. Why are these two estimates so different? Two things come to mind. The temporal resolution of the altimeter dataset is 7 days; for the subsampled $\mathrm{S}$ and BATS it is 30 days. However, we have filtered the altimeter data so that only the period band 4-12 months 

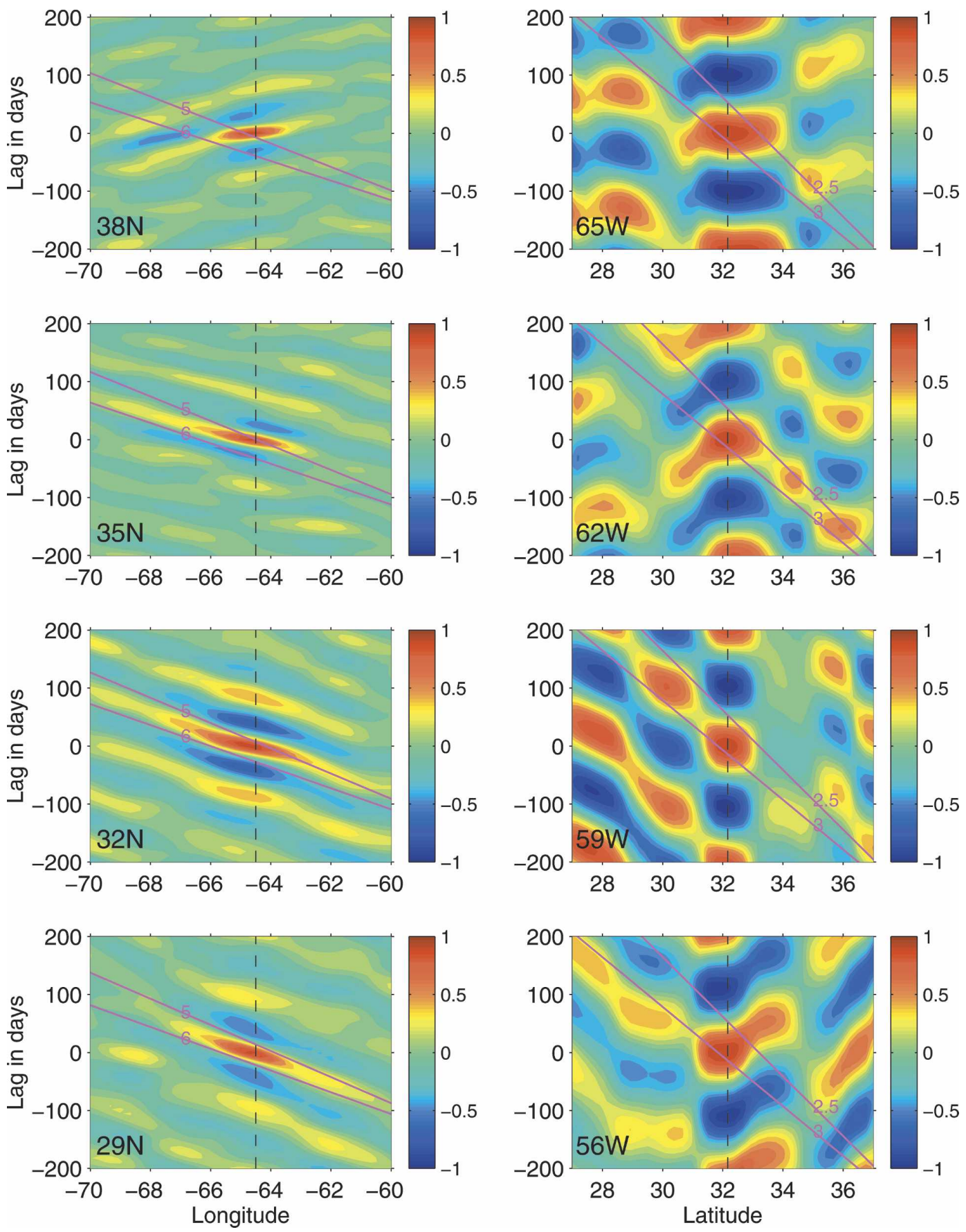

FIG. 15. (left) Lagged zonal ACF at four different latitudes for the period band $<4$ months. (right) Lagged meridional ACF at four longitudes for the period band 6-8 months.

is considered, which is directly comparable with the energetic periods in the station data. Second, S and BATS are only separated by $35 \mathrm{~km}$ zonally. The spatial resolution of the AVISO data is $13^{\circ}$, which would likely see $\mathrm{S}$ and BATS as a single point. It may be that the phase speeds measured by the altimeter and stations are for quite different scales of variability. This suggests a future avenue for exploration of the much-higherspatial-resolution along-track altimeter data near Bermuda. It also suggests that maintaining the two time series in parallel provides information on the characteristics of the mesoscale variability near Bermuda, which is not resolved even by the current golden age of satellite altimeter coverage. 


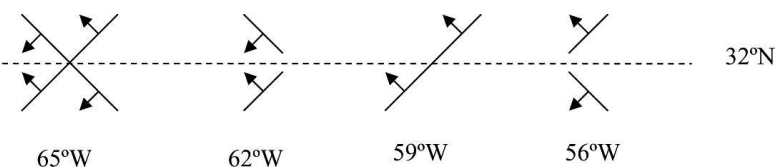

FIG. 16. Schematic of wave propagation at $32^{\circ} \mathrm{N}$ interpreted from lagged correlation analysis assuming that the patterns of correlation we see can be interpreted as baroclinic Rossby waves. The lines on the diagram represent wave crests; the arrows show the direction of propagation.

While the approach of this study has been a statistical one, it is interesting to look at individual events. Two particular time periods of $1 \mathrm{yr}$ have been selected to show some typicial "eddies" that are seen near Bermuda, both observed at one station and not the other. In the first example (Fig. 17, left), a cold core Gulf Stream ring is sampled in the $\mathrm{S}$ time series and can be identified by an elevated thermocline, a reduced thickness of $18^{\circ}$ Water, and low salinity in the upper layer. These rings, which form from meanders of the Gulf Stream, contain water from the north side of the Gulf Stream and have strong cyclonic flows. This same ring was not seen at BATS. A second example (Fig. 17, right) is a thick anticyclonic eddy of $18^{\circ}$ Water, similar to that documented by Brundage and Dugan (1986). This eddy is characterized by a deep thermocline and a
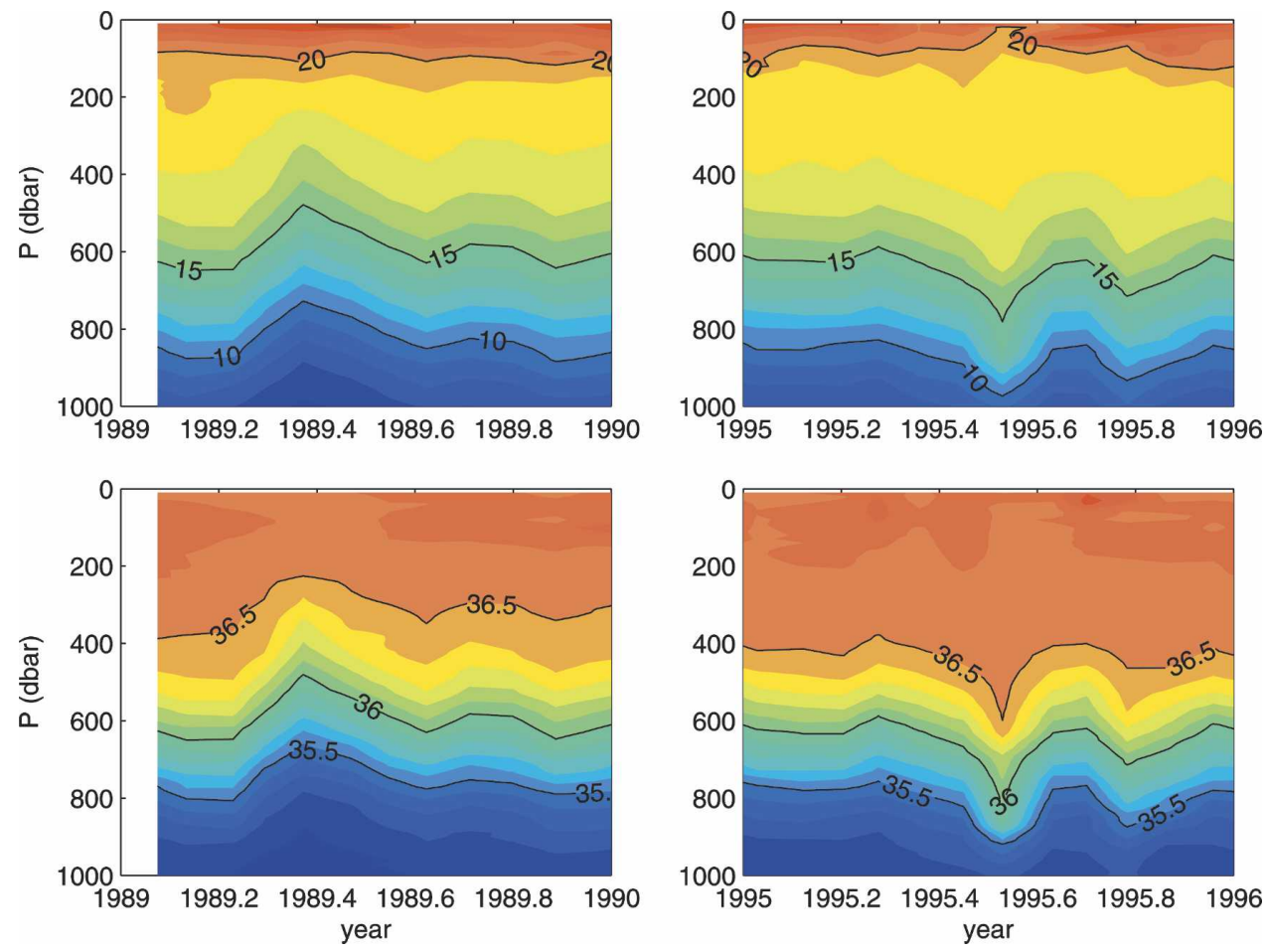

FIG. 17. Two examples of variability at Station S not seen at BATS and vice versa. (left) Temperature and salinity at Station S during 1989 showing a cold core Gulf Stream ring not detected at BATS. (right) Temperature and salinity at BATS during 1995 showing an $18^{\circ}$ Water lens not detected at Station S. 
quencies. Whether eddies or waves, this variability, having periods of a few months, is poorly sampled by the present BATS monthly time series. While S sampling at semimonthly periods better resolves this highfrequency signal, a preferable alternative would be to augment BATS with moored CTD observations having daily or better temporal resolution. One must then consider the trade-off between this highly resolved time series combined with continued monthly cruises to sample water at BATS and the alternative of continuing both BATS and S for the indefinite future.

Acknowledgments. We acknowledge support from NSF Grant OCE-0219644, the Australian Greenhouse Office, and CSIRO. We also thank Jane DunworthBaker for helping us with access to the various datasets; Mike Caruso for assistance with satellite altimeter data; the personnel at the Bermuda Biological Station, especially Rodney Johnson, for providing the hydrographic data; and Steve Rintoul, John Toole, Susan Wijffels, and one or two anonymous reviewers for valuable comments on the manuscript. The altimeter products were produced by the CLS Space Oceanographic Division.

\section{REFERENCES}

Brundage, W. L., and J. P. Dugan, 1986: Observations of an anticyclonic eddy of $18^{\circ} \mathrm{C}$ Water in the Sargasso Sea. J. Phys. Oceanogr., 16, 717-727.

Bryden, H. L., H. R. Longworth, and S. A. Cunningham, 2005: Slowing of the Atlantic meridional overturning circulation at $25^{\circ} \mathrm{N}$. Nature, 438, 655-657.

Chelton, D. B., R. A. deSzoeke, M. G. Schlax, K. El Naggar, and N. Siwertz, 1998: Geographical variability of the first baroclinic Rossby radius of deformation. J. Phys. Oceanogr., 28, 433-460.

Conkright, M. E., and Coauthors, 2002: Introduction. Vol. 1, World Ocean Database 2001, NOAA Atlas NESDIS 42, 160 pp.

Curry, R. G., M. S. McCartney, and T. M. Joyce, 1998: Oceanic transport of subpolar climate signals to mid-depth subtropical waters. Nature, 391, 575-577.

Dickson, R., J. Lazier, J. Meincke, P. Rhines, and J. Swift, 1996: Long-term coordinated changes in the convective activity of the North Atlantic. Progress in Oceanography, Vol. 38, Pergamon, 241-295.

_- I. Yashaeyev, J. Meincke, W. Turrell, S. Dye, and J. Holfort, 2002: Rapid freshening of the deep North Atlantic over the past four decades. Nature, 416, 832-837.

Emery, W. J., and R. E. Thomson, 2001: Data Analysis Methods in Physical Oceanography. Elsevier, 638 pp.

Frankignoul, C., 1981: Low-frequency temperature fluctuations off Bermuda. J. Geophys. Res., 86, 6522-6528.

Gill, A. E., 1982: Atmosphere-Ocean Dynamics. Academic Press, $662 \mathrm{pp}$.

Hurrell, J. W., Y. Kushnir, M. Visbeck, and G. Ottersen, 2003: An overview of the North Atlantic Oscillation. The North Atlan- tic Oscillation: Climate Significance and Environmental Impact, Geophys. Monogr., Vol. 134, Amer. Geophys. Union, $1-35$.

Jenkins, W. J., 1982: On the climate of a subtropical ocean gyre: Decadal timescale water mass renewal in the Sargasso Sea. $J$. Mar. Res., 40 (Suppl.), 265-290.

Joyce, T. M., and P. Robbins, 1996: The long-term hydrographic record at Bermuda. J. Climate, 9, 3121-3131.

— C. Deser, and M. A. Spall, 2000: The relation between decadal variability of subtropical mode water and the North Atlantic Oscillation. J. Climate, 13, 2550-2569.

— A. Aernandez-Guerra, and W. M. Smethie Jr., 2001: Zonal circulation in the NW Atlantic and Caribbean from a meridional World Ocean Circulation Experiment hydrographic section at $66^{\circ}$ W. J. Geophys. Res., 106 (C10), 22 095-22 113.

Killworth, P. D., D. B. Chelton, and R. A. deSzoeke, 1997: The speed of observed and theoretical long extratropical planetary waves. J. Phys. Oceanogr., 27, 1946-1966.

Kwon, Y.-O., and S. C. Riser, 2004: North Atlantic Subtropical Mode Water: A history of ocean-atmosphere interaction 19612000. Geophys. Res. Lett., 31, L19307, doi:10.1029/2004GL021116.

Le Traon, P.-Y., G. Dibarboure, and N. Ducet, 2001: Use of a high-resolution model to analyze the mapping capabilities of multiple-altimeter missions. J. Atmos. Oceanic Technol., 18, 1277-1288.

Molinari, R. L., D. A. Mayer, J. F. Festa, and H. F. Bezdek, 1997: Multiyear variability in the near-surface temperature structure of the midlatitude western North Atlantic Ocean. J. Geophys. Res., 102, 3267-3278.

Osychny, V., and P. Cornillon, 2004: Properties of Rossby waves in the North Atlantic estimated from satellite data. J. Phys. Oceanogr., 34, 61-76.

Qiu, B., W. Miao, and P. Müller, 1997: Propagation and decay of forced and free baroclinic Rossby waves in off-equatorial oceans. J. Phys. Oceanogr., 27, 2405-2417.

Reid, J. L., 1994: On the total geostrophic circulation of the North Atlantic Ocean: Flow patterns, tracers and transports. Progress in Oceanography, Vol. 33, Pergamon, 1-92.

Roemmich, D., 1990: Sea level and the thermal variability of the ocean. Sea Level Change, Studies in Geophysics, National Academy Press, 208-217.

Schroeder, E., and H. Stommel, 1969: How representative is the series of monthly mean conditions off Bermuda? Progress in Oceanography, Vol. 5, Pergamon, 31-40.

Siegel, D. A., D. J. McGillicuddy Jr., and E. A. Fields, 1999: Mesoscale eddies, satellite altimetry, and new production in the Sargasso Sea. J. Geophys. Res., 104, 13 359-13 379.

Smith, S. W., 2003: Digital Signal Processing. Elsevier, 650 pp.

Sturges, W., B. G. Hong, and A. J. Clarke, 1998: Decadal wind forcing of the North Atlantic subtropical gyre. J. Phys. Oceanogr., 28, 659-668.

Talley, L. D., 1996: North Atlantic circulation and variability, reviewed for the CNLS Conference. Physica D, 98, 625-646.

_, and M. E. Raymer, 1982: Eighteen Degree Water variability. J. Mar. Res., 40 (Suppl.), 757-775.

U.S. JGOFS Steering Committee, 1990: Global ocean flux study long range plan. $71 \mathrm{pp}$. and appendixes.

Worthington, L. V., 1959: The 18 Degree Water in the Sargasso Sea. Deep-Sea Res., 5, 297-305.

Wunsch, C., 1972: Bermuda sea level in relation to tides, weather, and baroclinic fluctuations. Rev. Geophys., 10, 1-49. 